\title{
Evaluation of Dexmedetomidine Co-Administered with Neostigmine and Bupivacaine for Postoperative Epidural Analgesia in Lower Limb Orthopaedic Surgeries - A Study from Maharashtra, India
}

\author{
Parag Yashawant Dongre ${ }^{1}$, Aruna Vijay Chandak², Amol P. Singam³ \\ 1, 2,3 Department of Anaesthesia, Jawaharlal Nehru Medical College, DMIMS, Sawangi, Maharashtra, India.
}

\section{ABSTRACT}

\section{BACKGROUND}

Addition of adjuvants to the neuro axial blocked helps prolongate the duration and quality of analgesia and anaesthesia. The safety and efficacy of drugs dexmedetomidine and neostigmine have been less commonly studied. We wanted to compare post-operative analgesia, haemodynamics, and side effects if any in this study.

\section{METHODS}

Combined spinal - epidural anaesthesia was performed in 60 patients who underwent lower limb surgeries of less than $2 \mathrm{hrs}$. The patients were given the drug epidurally post-surgery. Group I, II and III were given $10 \mathrm{ml}$ of $0.25 \%$ bupivacaine alone, with 1 microgram per $\mathrm{kg}$ of neostigmine and with 0.5 milligram per $\mathrm{kg}$ of dexmedetomidine and 1 microgram per $\mathrm{kg}$ of neostigmine, respectively. $50 \mathrm{mg}$ tramadol intravenous was kept as rescue analgesic. Parameters which predict haemodynamics, assessment of pain, period of analgesia, demand for rescue analgesia and the chances of side effects were noted over the next ten hrs.

\section{RESULTS}

To conclude, epidural analgesia is the most preferred analgesia these days in management of lower limb orthopaedic surgery's post-operative pain. When bupivacaine was combined with neostigmine and dexmedetomidine as a neuraxial adjuvant, it prolonged the post-operative analgesia significantly without increasing the side effects of those drugs. The combination of two drugs proved better than the use of single drug alone.

\section{CONCLUSIONS}

Combination of neostigmine and dexmedetomidine when used as a neuraxial adjuvant, significantly prolonged the duration of post-operative analgesia by 274.13 4.539 in lower limb orthopaedic cases compared to neostigmine alone that was $176.23 \pm 3.441$.

\section{KEY WORDS}

Epidural, Neostigmine, Dexmedetomidine, Orthopaedic Surgeries, Post-Operative Analgesia
Corresponding Author:

Dr. Parag Yashawant Dongre,

Department of Anaesthesia,

Jawaharlal Nehru Medical College,

DMIMS, Sawangi,

Maharashtra, India.

E-mail: paragdongre21@gmail.com

DOI: $10.14260 /$ jemds/2021/539

How to Cite This Article:

Dongre $P Y$, Chandak AV, Singam AP. Evaluation of dexmedetomidine coadministered with neostigmine and bupivacaine for post-operative epidural analgesia in lower limb orthopaedic surgeries - a study from Maharashtra, India. $J$ Evolution Med Dent Sci 2021;10(32):2634-2639, DOI: $10.14260 /$ jemds $/ 2021 / 539$

Submission 16-11-2020,

Peer Review 08-06-2021,

Acceptance 15-06-2021,

Published 09-08-2021.

Copyright (C) 2021 Parag Yashawant Dongre et al. This is an open access article distributed under Creative Commons Attribution License [Attribution 4.0 International (CC BY 4.0)] 


\section{BACKGROUND}

International association of the study of pain (IASP) defined pain as an unpleasant sensory or emotional experience which is associated with actual or potential tissue damage or described in terms of such damage". ${ }^{1}$

If two patients are undergoing the same procedure, they will have different threshold for pain. Majority of the orthopaedic procedures are carried out under regional anaesthesia, such as central neuraxial blockade, nerve blocks. Regional anaesthesia not only gives benefits over general anaesthesia but also allows the patient to mobilise out of the bed faster, for physiotherapy and other supportive therapies. Alleviation of pain during and after surgery plays an important role in surgical outcome of the patients. Effective optimisation of postoperative analgesia in orthopaedic patients can reduce morbidity and mortality by providing patient comfort and satisfaction. Early mobilization thus also contributes to less chances of deep venous thrombosis and other embolic events, faster recovery rate, less likelihood of development of chronic neuropathic pain at lower cost and with less duration hospital stay. ${ }^{2}$

\section{Pharmacological Methods}

Include administration of drugs like opioids, non-opioids and adjuvants (ketamine, clonidine, neostigmine) parenterally or they can be administered via regional anaesthetic techniques such as epidurals, continuous nerve blocks, and local infiltrations.

\section{Non-Pharmacological Methods}

They include transcutaneous nerve stimulation, acupuncture, hot and cold fomentation, acupressure, meditation etc. ${ }^{3}$ As opioids given intravenously have numerous side effects such as respiratory depression and bradycardia and NSAIDS are known to cause damage to the kidneys, we have studied epidural administration of a local anaesthetic, bupivacaine hydrochloride which is an aminoamide local anaesthetic. It is chemically known as ( \pm ) - 1 butyl 1 - 2 - piperidyl form - 2'6' xylidine hydrochloride. ${ }^{4}$ Bupivacaine was synthesized by Swedish Investigators Af Ekenstam et al. It is a white crystalline powder soluble in water. Bupivacaine acts in the similar manner like any local anaesthetic. The main action of anaesthetics which are locally acting is on the axon's cell membrane, where it stabilises electrically. ${ }^{5}$ The temporary rise in permeability to $\mathrm{Na}^{+}$ions, needed for the transmission of impulse, is prevented. Hence, the action potential at rest is preserved and their inhibition to depolarization in response to application of stimuli. ${ }^{6}$

Dexmedetomidine is an enantiomer of medetomidine which can rotate the plane of light to right, and is the methylated derivative of etomidine, 7 its specificity for the $\alpha-2$ receptor is 8 times more compared to clonidine, with an $\alpha-2$ : $\alpha-1$ binding affection ratio of 1620: 1 and its consequences are dependent on the amount of drug and can be returned to normal by giving of a selective $\alpha-2$ antagonist such as atipamezole. ${ }^{7}$

Neostigmine's mechanism is by inhibition of the hydrolysis of Ach, 8 in a competitive fashion gets attached to the site of ester of acetylcholinesterase. ${ }^{9,10}$ It gets collected, acetylcholine and increases the choline like action and helps in impulse transmission. In this study we have evaluated the effects of adjuvants like dexmedetomidine and neostigmine to bupivacaine for elongation of the post-operative analgesia and its side effects. ${ }^{11}$

\section{METHODS}

The present study is a prospective, comparative, interventional study. It was conducted in Acharya Vinoba Bhave rural hospital attached to Jawaharlal Nehru Medical University, Sawangi, Meghe, Wardha, Maharashtra during the period of August 2018 to September 2020. A preprocedural systemic clinical examination was done and written informed consent was obtained from the patients who underwent lower limb surgeries in orthopaedics and out of these patients only, 60 were selected from the ASA class 1 and 2 groups by chit system randomly, and were requested for spinal plus epidural anaesthesia. These were then randomly divided into 30 patients each in 2 groups and, were named group $\mathrm{N}$ and group ND respectively receiving only neostigmine and combination of neostigmine and dexmedetomidine.

Group N - Thirty patients who received $10 \mathrm{ml}$ of $0.125 \%$ of bupivacaine with $1 \mathrm{mcg}$ / kg of neostigmine, epidurally.

- Group ND - Thirty patients who received $10 \mathrm{ml}$ of $0.125 \%$ of bupivacaine with $0.5 \mathrm{mcg} / \mathrm{kg}$ of dexmedetomidine and 1 mcg / kg of neostigmine, epidurally.

\section{Inclusion Criteria}

a) Patients aged between 18 and 50years

b) ASA Grade I \& II patients.

c) Those who were willing to give written informed consent

d) Both male and female patients.

\section{Exclusion Criteria}

a) ASA Grade III and above

b) Patients with haemorrhagic diathesis.

c) Patients with renal, cardiac, pulmonary or neurological dysfunction

d) Patients with hepatic dysfunction.

e) Age: $<18 \&>50$ years (male or female)

f) Patients having allergy to test drugs

g) Patients with significant scoliosis or kyphosis

h) Patients who refused to give written and informed consent

i) Pregnant patients.

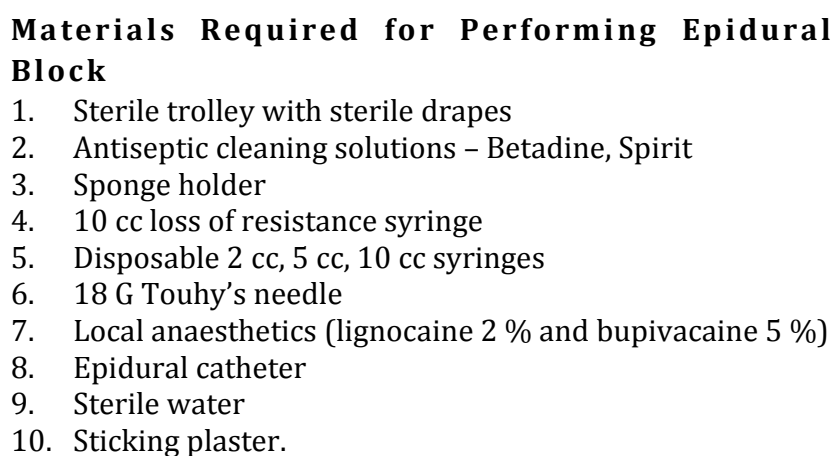


All patients were clinically examined, and their detailed history was obtained. Patients were tested for the regular routine parameters of blood with coagulation profile. All the basic vitals like pulse, systolic and diastolic pressures, electrocardiogram, Sp02, were monitored and noted. Hypersensitivity test for lidocaine was performed. 18G intravenous cannula was secured in each of these patients. Patients were pre-loaded before the induction with $10 \mathrm{ml} / \mathrm{kg}$ of ringer's lactate. They were given sitting position and were cleaned, painted and draped, under all aseptic precautions. 2 $\%$ lidocaine was injected locally, for analgesia and the epidural catheter was covered with a sterile piece of gauge. Patients were given sub arachnoid block with the help of 25G Quincke's needle in L3 - L4 intervertebral space. The Quincke's needle was progressed inwards with the upward facing bevel till the dura was pierced.

Then the flow of CSF was confirmed by removing the stylet from the spinal needle. After meticulous withdrawal of cerebrospinal fluid, the desired drug was introduced into the subarachnoid space. Then the patient was made into the supine position immediately and T8 level was taken for all the patients. Epidural top up was given after 4 segment regression of the spinal effect or when the surgery was over. Duration of surgery was kept around 2 hrs for all the patients. Any surgeries exceeding and falling short of the duration were excluded from the study. Epidural catheters placement was confirmed for any intravascular migration by administering test dose of lignocaine and adrenaline $(3 \mathrm{ml})$ after negative aspiration of the catheter.

The drug administration was done as mentioned below

- Group N - Thirty patients who received $10 \mathrm{ml}$ of $0.125 \%$ of bupivacaine with $1 \mathrm{mcg}$ / $\mathrm{kg}$ of neostigmine, epidurally, after 4 segment regression of sub-arachnoid block (SAB)

- Group ND - Thirty patients who received $10 \mathrm{ml}$ of 0.125 $\%$ of bupivacaine with $0.5 \mathrm{mcg} / \mathrm{kg}$ of dexmedetomidine and $1 \mathrm{mcg} / \mathrm{kg}$ of neostigmine, epidurally, after 4 segment regression of $\mathrm{SAB}$

Patients heart rate, systolic blood pressure, diastolic blood pressure, respiratory rate, visual analogy score, sedation score, time of rescue analgesia were recorded. Inj tramadol was kept as a rescue analgesia in case patient complains of pain in the post-operative period.

\section{RESULTS}

\begin{tabular}{|c|c|c|c|c|}
\hline \multirow{2}{*}{$\begin{array}{l}\text { Duration of } \\
\text { Analgesia }\end{array}$} & \multicolumn{2}{|c|}{ Group } & \multirow[b]{2}{*}{ Total } & \multirow[b]{2}{*}{$\begin{array}{l}\text { T test } \& \\
\text { P Value }\end{array}$} \\
\hline & $\begin{array}{c}\text { Dexmed } \\
+ \text { NEO }\end{array}$ & NEO & & \\
\hline Less Than 250 & $0(0.0 \%)$ & $30(100.0 \%)$ & $30(50.0 \%)$ & $\mathrm{T}=-94.143$ \\
\hline More Than 250 & $30(100.0 \%)$ & $0(0.0 \%)$ & $30(50.0 \%)$ & p - value < \\
\hline Total & $30(100.0 \%)$ & $30(10$ & $\%)$ & \\
\hline Mean \pm SD & $274.13 \pm 4.539$ & $176.23 \pm 3.441$ & & 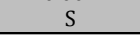 \\
\hline \multicolumn{5}{|c|}{$\begin{array}{c}\text { Table 1. Distribution of Study Participants } \\
\text { Based on Duration of Analgesia }\end{array}$} \\
\hline \multicolumn{5}{|c|}{$\begin{array}{l}\text { The table displays the duration of analgesia in the two groups, in group } \mathrm{N} \\
\text { the mean was } 176.23 \pm 3.441 \text { and in group ND the mean came out to be } \\
274.13 \pm 4.539 \text {. It was found to be statistically significant with the P value } \\
\text { of }<0.001 \text {. }\end{array}$} \\
\hline
\end{tabular}

Parameters like age, weight, gender, type of surgeries were found as not statistically significant. Difference in the mean ages of the subjects, weights of patients, gender distribution of the patients and types of surgeries were included in the study as the P value was $<0.005$.

\section{Comparison of Mean of Pulse Rate between the Groups}

The mean heart rate of the subjects who participated in the study, and the heart rate were monitored for $24 \mathrm{hrs}$ in the post- operative period. It was seen that there was a statistically significant comparison between the two groups, group $\mathrm{N}$ and group ND, with group ND showing better control on heart rate than in group $\mathrm{N}$.

\section{Comparison of Mean of Systolic Blood Pressure between the Groups}

It shows a statically significant difference between the two groups, and systolic blood pressure was on a slight lower side in group ND compared to group $\mathrm{N}$.

\section{Comparison of Mean of Diastolic Blood Pressure between the Groups}

It was seen that there was statistically significant reduction in diastolic blood pressure in Group ND compared to Group N.

\section{Sedation Score}

\begin{tabular}{|c|c|c|c|}
\hline $\begin{array}{l}\text { Time } \\
\text { Interval }\end{array}$ & $\begin{array}{l}\text { Group DEXMED } \\
\quad+\text { NEO } \\
\text { (Mean } \pm \text { SD) }\end{array}$ & $\begin{array}{l}\text { Group NEO } \\
\text { (Mean } \pm \text { SD) }\end{array}$ & T test $\&$ P Value \\
\hline 0 Hour & $1.83 \pm 0.379$ & $1 \pm 0$ & $\mathrm{~T}=-12.042, \mathrm{p}$ \\
\hline $1 \mathrm{Ho}$ & & 46 & $0.001 \mathrm{~s}$ \\
\hline 2 Hours & 607 & & $\mathrm{~T}=-7.757, \mathrm{~F}$ \\
\hline 4 Hours & & \pm 0.450 & $\mathrm{~T}=-7.908, \mathrm{p}-$ value $<0.001 \mathrm{~S}$ \\
\hline 6 Hours & $7 \pm($ & $1.87 \pm 0.629$ & $\mathrm{~T}=-4.616$ \\
\hline 8 Hours & & 2. & $0.001 \mathrm{~S}$ \\
\hline $12 \mathrm{H}$ & & & $01 \mathrm{~s}$ \\
\hline 16 Hours & 91 & $2 \pm 0.743$ & $\mathrm{~T}=-3.958, \mathrm{p}$ \\
\hline 20 Hours & $2.43=$ & $2.13 \pm 0.629$ & $\mathrm{~T}=-1.852, \mathrm{p}-\mathrm{v}$ \\
\hline 24 Hours & $2.17 \pm 0.592$ & $2.3 \pm 0.702$ & $\mathrm{~T}=0.795, \mathrm{p}-$ value $=0.43 \mathrm{NS}$ \\
\hline \multicolumn{4}{|c|}{ Table 2. Comparison of Mean of Sedation Score between the Groups } \\
\hline \multicolumn{4}{|c|}{$\begin{array}{l}\text { Table } 2 \text { shows the mean Ramsay Sedation Score in both group } \mathrm{N} \text { and group } \\
\text { ND, which shows that they are statistically significant in comparison with } \\
\text { group ND showing more sedation than group N. }\end{array}$} \\
\hline
\end{tabular}

\section{VAS Score}

\begin{tabular}{|c|c|c|c|}
\hline $\begin{array}{c}\text { Time } \\
\text { Interval }\end{array}$ & $\begin{array}{c}\text { Group N } \\
(\text { Mean } \pm \text { SD) }\end{array}$ & $\begin{array}{c}\text { Group ND } \\
\text { (Mean } \pm \text { SD) }\end{array}$ & T Test \& P Value \\
\hline 0 Hour & $1.37 \pm 0.718$ & $1.43 \pm 0.504$ & $\mathrm{~T}=0.416, \mathrm{p}$ \\
\hline $1 \mathrm{H}$ & & & \\
\hline $2 \mathrm{Hou}$ & 29 & & $T=$ \\
\hline $4 \mathrm{Ho}$ & & & $1 \mathrm{~s}$ \\
\hline 6 Hours & 3 & 1. & $T=-8$ \\
\hline $8 \mathrm{H}$ & 8 & & $T=-1$ \\
\hline $12 \mathrm{H}$ & & & \\
\hline $16 \mathrm{l}$ & & & $T=-$ \\
\hline $20 \mathrm{Ho}$ & 1.90 & $1.73 \pm$ & $\mathrm{T}=-1.208$ \\
\hline 24 Hours & $1.63 \pm 0.490$ & $1.77 \pm 0.568$ & $\mathrm{~T}=0.973, \mathrm{p}-$ value $=0.335 \mathrm{NS}$ \\
\hline \multicolumn{4}{|c|}{ Table 3. Comparison of Mean of VAS between the Groups } \\
\hline \multicolumn{4}{|c|}{$\begin{array}{l}\text { Table } 3 \text { shows comparison of mean visual analogue score of patients in } \\
\text { both the groups, group } N \text { and group ND. It shows that they are statistically } \\
\text { significant in comparison with the P values }<0.05 \text {. }\end{array}$} \\
\hline
\end{tabular}



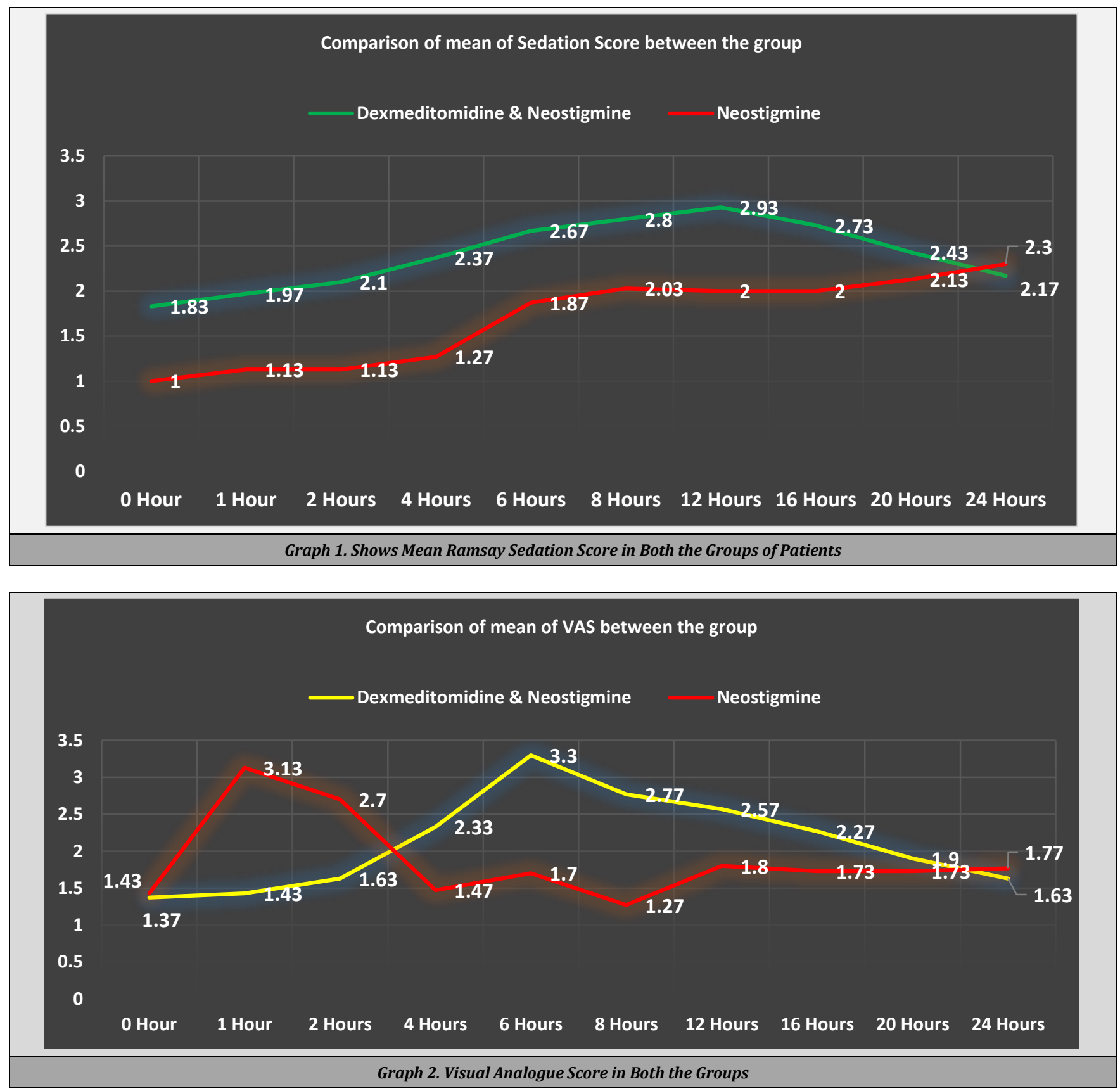

\section{Side Effects}

\begin{tabular}{|c|c|c|c|c|}
\hline \multicolumn{5}{|c|}{ Group } \\
\hline $\begin{array}{l}\text { Siae } \\
\text { Effects }\end{array}$ & $\begin{array}{l}\text { Dexmedetomidine } \\
\text { \& Neostigmine }\end{array}$ & Neostigmine & \multicolumn{2}{|l|}{ Total } \\
\hline NIL & $28(93.3 \%)$ & $28(93.3 \%)$ & $56(93.3 \%)$ & \multirow{3}{*}{$\begin{array}{c}\text { Fisher Exact test } \\
\text { applied } \\
\text { P - Value }=0.694 \\
\text { NS }\end{array}$} \\
\hline Nausea & $2(6.7 \%)$ & $2(6.7 \%)$ & $4(6.7 \%)$ & \\
\hline Total & $30(100.0 \%)$ & $30(100.0 \%)$ & $60(100.0 \%)$ & \\
\hline \multicolumn{5}{|c|}{ Table 4 Comparison of Side Effects in Both Groups } \\
\hline
\end{tabular}

The above - mentioned table describes the side effects in each of the groups which were $6.7 \%$, and were statistically not significant with the $\mathrm{p}$ value of 0.69 .

\section{Sample Size Calculation}

It was calculated by open epi app which came out to be 48 and considering dropouts it was taken to be 60 , We conducted a prospective, comparative study in 60 patients, who were willing to give the consent for epidural and spinal anaesthesia.

\section{DISCUSSION}

The following parameters were monitored in the patients in each of the group; Demographic data - The two groups were comparable with respect to their physical parameters. The mean age of the study population in the group $\mathrm{N}$ was $36.4 \pm$ 12.66 and in the group ND was $35.27 \pm 15.39$. There was no statistical significance as the $\mathrm{P}$ - value was 0.756 . The mean weight of the patients in the group $\mathrm{N}$ was $68.07 \pm 4.18$ and in the group ND $69.17 \pm 3.56$.

There was no statistical significance as the comparison of them came to the $\mathrm{P}$ value of 0.312 . The gender wise distribution in group $\mathrm{N}$, was males $80 \%$ and females were 20 
$\%$, and in group ND males were $63.3 \%$ and females were 36.7 $\%$. There was no statistical significance in the gender distribution as the $\mathrm{P}$ value was 0.126 .

\section{Duration of Analgesia}

Our choice of the doses of the drugs which were safe were decided on the basis of previous use of these doses by Ashima Sharma et al. ${ }^{12}$ who used $0.5 \mathrm{mcg} / \mathrm{kg}$ dexmedetomidine and 1 mcg / kg of neostigmine epidurally in lower limb orthopaedic surgeries. The first group N (Neostigmine) which had mean duration of analgesia as $176.23 \pm 3.441$ mins, there was statistically significant prolongation of duration in group ND which was $274.13 \pm 4.539$ mins.

The combination of these two drugs provided better and prolonged post-operative analgesia in lower limb orthopaedic patients. The mean duration of analgesia in the group $\mathrm{N}$ was $176.23 \pm 3.441$ and in group ND was $274.13 \pm 4.539$, there was a statistically significant difference between the duration of analgesia of the two groups as the P value was $<0.001$.

Roelants and Fabienne ${ }^{13}$ in a study dated June 2006 on the use of neuraxial adjuvant drugs (neostigmine, clonidine) in obstetrics neuraxial adjuvant drugs were used to improve analgesia and to decrease complications associated with a high dose of a single drug. Similar on these lines we have combined two drugs neostigmine and dexmedetomidine which showed similar results of significantly prolonging the analgesia as compared to single drug alone.

\section{Haemodynamics}

Shows comparison of pulse rates in both the groups at the intervals of $0,1,2,4,6,8,12,16,20$ and $24 \mathrm{hrs}$, where in group $\mathrm{N}$ and in group ND the mean pulse rate comparison was statistically significant as the $\mathrm{p}$ value was $<0.001$ through the post-operative period and showed better stability in group ND and was on the slightly lower side.

Shows systolic blood pressure comparison in both groups of study, the values were assessed at the intervals of $0,1,2,4$, $6,8,12,16,20$, and $24 \mathrm{hrs}$. This table shows comparison of mean systolic blood pressure between the two groups $\mathrm{N}$ and ND, which was statistically significant throughout the postoperative period and was on slightly lower side in Group ND.

Shows comparison between mean diastolic blood pressure in two groups, group $\mathrm{N}$ and group ND at the intervals of $0,1,2$, $4,6,8,12,16,20$ and $24 \mathrm{hrs}$. In this table till $2^{\text {nd }} \mathrm{hr}$ the comparison between the two groups was not significant but $2^{\text {nd }} \mathrm{hr}$ onwards the comparison between the two groups was significant and was on slightly lower side in group ND than in group $\mathrm{N}$.

In the study conducted by Ashima Sharma et al. ${ }^{12}$ in the year 2016 showed similar results where dexmedetomidine neostigmine group showed better haemodynamic stability compared to neostigmine and bupivacaine alone. Neostigmine, if given via neuraxial route increases outflow of sympathetic system, thus cross reacts with the hypotension because of bupivacaine and alpha 2 agonist induced bradycardia. ${ }^{11}$ Dexmedetomidine epidurally causes sympatholytic, thereby decreasing $\mathrm{HR}$ and $\mathrm{BP}$ in a dose-dependent manner, documented in a systematic review and metanalysis by $\mathrm{Wu}$ et al. ${ }^{3}$

\section{Visual Analogue Score}

Shows comparison of the mean visual analogue score in both the groups in our study at the intervals of $0,1,2,4,6,8,12,16$, 20 , and 24 hrs. It shows statistically significant values of comparison between the two groups except for $20^{\text {th }} \mathrm{hr}$ onwards as the $\mathrm{P}$ value was $<0.001$. The score was better in group ND, and showed better analgesic profile. In the study conducted by shaikh and Mahesh et al. ${ }^{4}$ in 2016, they came up with similar results of dexmedetomidine being the superior neuraxial adjuvant in epidural analgesia in orthopaedic surgeries and had better VAS compared to clonidine in the study which was statistically significant. Chiruvella et al. ${ }^{5}$ in their study conducted in the year 2018 compared dexmedetomidine with clonidine (an alpha agonist), and they came up with conclusion that, dexmedetomidine produced better and prolonged analgesic effect compared to clonidine in total abdominal hysterectomies. According to Ashima Sharma et al. ${ }^{12}$ who published a study on lower limb orthopaedic surgeries in the year 2016, showed better VAS in Group 3 which had dexmedetomidine and neostigmine combined with bupivacaine compared to neostigmine and bupivacaine alone when given as neuraxial adjuvant epidurally.

\section{Sedation Score}

Depicts the trend of sedation in the patients who were participating in the study, and shows that the Ramsay Sedation Score was less in the group $\mathrm{N}$ compared to group ND. This data was statistically significant with $P$ values $<0.001$ except for the VAS after $20^{\text {th }} \mathrm{hr}$ post-operatively. Akin et al. ${ }^{6}$ in a study conducted in the year 2008, concluded on the similar lines in their study.

Ashima Sharma et al. ${ }^{12}$ in the year 2016 conducted a study and concluded with their observations that, in their study there was no statistically significant difference in comparison of sedation scores with dexmedetomidine. But in our study, we have concluded that the sedation score comparison was significant.

\section{Side Effects}

Displays the side effects that occurred in our study groups, both the groups had nausea as the side effect and was observed in $6.7 \%$ of cases in each group and the comparison was statistically not significant with the $\mathrm{p}$ value more than 0.05 .

\section{CONCLUSIONS}

To conclude, epidural analgesia is most preferred these days in the management of lower limb orthopaedic surgeries postoperative pain. When bupivacaine was combined with neostigmine and dexmedetomidine as a neuraxial adjuvant, it prolonged the post-operative analgesia significantly without increasing the side effects of those drugs. The combination of the two drugs proved better than use of the single drug alone. 
Data sharing statement provided by the authors is available with the full text of this article at jemds.com.

Financial or other competing interests: None.

Disclosure forms provided by the authors are available with the full text of this article at jemds.com.

\section{REFERENCES}

[1] Treede RD. The International Association for the study of pain definition of pain: as valid in 2018 as in 1979, but in need of regularly updated footnotes. Pain Rep 2018;3(2):e643.

[2] Roelants F, Lavand'homme PM. Epidural neostigmine combined with sufentanil provides balanced and selective analgesia in early labor. Anesthesiology 2004;101(2):439-44.

[3] Wu HH, Wang HT, Jin JJ, et al. Does dexmedetomidine as a neuraxial adjuvant facilitate better anesthesia and analgesia? A systematic review and meta-analysis. PLoS One 2014;9(3):e93114.

[4] Shaikh SI, Mahesh SB. The efficacy and safety of epidural dexmedetomidine and clonidine with bupivacaine in patients undergoing lower limb orthopedic surgeries. J Anaesthesiol Clin Pharmacol 2016;32(2):203-9.

[5] Chiruvella S, Donthu B, Nallam SR, et al. Postoperative analgesia with epidural dexmedetomidine compared with clonidine following total abdominal hysterectomies: a prospective double-blind randomized trial. Anesth Essays Res 2018;12(1):103-8.
[6] Akin S, Aribogan A, Arslan G. Dexmedetomidine as an adjunct to epidural analgesia after abdominal surgery in elderly intensive care patients: a prospective, doubleblind, clinical trial. Curr Ther Res 2008;69(1):16-28.

[7] Chestnut DH, McGrath JM, Vincent RD, et al. Does early administration of epidural analgesia affect obstetric outcome in nulliparous women who are in spontaneous labor? Anesthesiology 1994;80(6):1201-8.

[8] Zhao Y, Xin Y, Liu Y, et al. Effect of epidural dexmedetomidine combined with ropivacaine in labor analgesia. Clin J Pain 2017;33(4):319-24.

[9] Giovannitti Jr JA, Thoms SM, Crawford JJ. Alpha-2 adrenergic receptor agonists: a review of current clinical applications. Anesth Prog 2015;62(1):31-9.

[10] Park JW, Bae SK, Huh J. Distance from dura mater to spinal cord at the thoracic vertebral level: an introductory study on local subdural geometry for thoracic epidural block. J Int Med Res 2016;44(4):950-6.

[11] Colovic MB, Krstic DZ, Lazarevic-Pasti TD, et al. Acetylcholinesterase inhibitors: pharmacology and toxicology. Curr Neuropharmacol 2013;11(3):315-35.

[12] Sharma A, Kumar NJ, Azharuddin M, et al. Evaluation of low-dose dexmedetomidine and neostigmine with bupivacaine for postoperative analgesia in orthopedic surgeries: a prospective randomized double-blind study. J Anaesthesiol Clin Pharmacol 2016;32(2):187-91.

[13] Roelants F. The use of neuraxial adjuvant drugs (neostigmine, clonidine) in obstetrics. Curr Opin Anesthesiol 2006;19(3):233-7. 